\title{
Comparative molecular genetic diversity between Trichoderma spp. from Egypt and Saudi Arabia
}

\author{
Yasser S. A. Mazrou ${ }^{1,2}$, Alaa Baazeem³ ${ }^{3}$, Abeer H. Makhlouf ${ }^{4}$, Ayman Sabry ${ }^{3,5}$, Mohamed Ismail ${ }^{6}$ and \\ Mohamed M. Hassan ${ }^{3,6^{*}}$ (D)
}

\begin{abstract}
Background: The phylogeny and phylogenetic relationships of Trichoderma species were investigated by many methods including maximum parsimony and distance analysis of DNA sequences from multiple genetic loci. 5.85 rDNA sequence analysis is a powerful tool in evolution studies.

Main body: The aim of this study was to identify and determine the genetic distance between 36 Trichoderma isolates from Egyptian and Saudi Arabian soils based on their 5.8S rDNA sequences. The genetic diversity of Trichoderma (Hypocreales, Ascomycota) species from Egypt and Saudi Arabia was investigated. The DNA barcoding of 36 isolates, based on the internal transcribed spacers 1 and 4 (ITS1 and 4) of the ribosomal RNA gene cluster and the partial sequence of this gene, revealed the diversity of these isolates. BLAST query showed that two species, namely $T$. longibarchiatum (42.7\% of the isolates) and T. lentiforme (33.3\% of the isolates), pre-dominated the isolates. Variation among specimens of the same species was detected. Cluster analysis of the Egyptian isolates showed two groups; the first group was subdivided into two subgroups, the first of which included T. lentiforme and T. crassum isolates, and the second subgroup harbored T. Iongibrachiatum, T. pseudokoningii, and T. bissettii. The second group included T. neokoningii and T. yunnanens. The cluster analysis of isolates from Saudi Arabia also consisted of two groups. The first group was subdivided into two subgroups; the first included T. longibrachiatum and T. pseudokoningii. The second subgroup harbored T. simmonsii and T. lentiforme. Also, no correlation between genetic and geographic distance was detected.
\end{abstract}

Conclusion: The results of the present study indicated that the Saudi Arabian isolates showed greater nucleotide diversity compared to Egyptian isolates. Also, these findings will assist in future studies while assessing Trichoderma genetic diversity.

Keywords: Trichoderma, Nucleotide diversity, Cluster analysis, Saudi Arabia, Egypt

\section{Background}

One of the main goals of the agricultural development is to secure enough food to the growing population worldwide, where the use of biotechnology is essential in this context (Mazrou et al. 2020). The most significant agricultural-related problems in Egypt is the decrease in

\footnotetext{
* Correspondence: khyate_99@yahoo.com

${ }^{3}$ Department of Biology, College of Science, Taif University, P.O. Box 11099, Taif 21944, Saudi Arabia

${ }^{6}$ Department of Genetics, Faculty of Agriculture, Menoufia University, Sheben El-Kom, Menoufia Government, Egypt

Full list of author information is available at the end of the article
}

edible crops in the presence of an increasing population, the erosion of agricultural lands, and the loss of crops associated with diseases and pathogens (Hassan 2014 and Mazrou et al. 2020). One promising resolution to tackle these problems depends on the use of biological control. The term biological control means the use of biological materials to control plant-causing biological diseases and increase crop productivity (Hassan et al. 2019). Trichoderma spp. are of great benefit to Egyptian and Saudi Arabian agriculture. Trichoderma has many beneficial properties such as being environmentalfriendly fungi, a biological control agent, and a promoter 
of plant growth. Several Trichoderma species (e.g., T. bissettii, T. crassum, T. lentiforme, T. longibrachiatum, T. neokoningii, T. pseudokoningii, and T. yunnanens) are effective biocontrol agents due to their ability to inhibit pathogen growth in soil (Atanasova et al. 2013; Kredics et al. 2014; Parmar et al. 2015). These species help to the overall of the plant antagonistic microorganisms. Trichoderma spp. reduce the growth and survival of pathogens through various mechanisms such as competition antibiosis, mycoparasitism, hyphal interactions, and enzyme secretion. Such microorganisms are now available commercially and are used in crop management and practices (Atanasova et al. 2013; Parmar et al. 2015). There are many difficulties in the morphological identification of Trichoderma due to the homoplasy of morphological and phenetic characters, particularly among the Trichoderma anamorph forms; hence, the molecular methods offer a dependable way to identify Trichoderma species (Hassan et al. 2014; Lakhani et al. 2016). Molecular identification and characterization of fungal genomes are generally performed with a universal set of internal transcribed spacer (ITS) markers that amplify the specified $5.8 \mathrm{~S}$ $r R N A$ fragment of the fungal DNA. The ITS region of nuclear DNA is currently selected as the standard marker for fungal DNA barcoding and for analyzing fungal diversity (Schoch et al. 2012; Hassan 2014). Hassan et al. (2019) improved the use of sequence-characterized amplified region (SCAR) markers as a simple marker system that enables rapid and inexpensive species identification which contributed to overcome Trichoderma identification difficulties. Molecular identification of fungal species using molecular techniques such as DNA barcoding has gained considerable attention; therefore, the International Union of Microbiological Societies hosts an official website, namely the International Sub-commission on Trichoderma and Hypocrea Taxonomy (http://isth.info/). This website is designed as an open resource to host the most recent data on Hypocreal Trichoderma taxonomy and evolution. Additionally, this website presents a collection of user-friendly tools for the rapid molecular identification of Hypocrea/Trichoderma based on DNA barcode. The TrichOKEY and TrichoBLAST databases are available on the website, which can assist in the quick identification of Trichoderma/Hypocrea species, using ITS anchors (Srivastava et al. 2014; Fahmi et al. 2016).

To date, a limited number of ITS gene sequence are used for the molecular identification of the fungal genus Trichoderma. However, the use of these gene sequences is limited to the successful and accurate identification of only a few species (Hassan 2014; Fahmi et al. 2016; Hassan et al. 2019). Moreover, few studies dealt with the genetic diversity of Trichoderma in Egypt and Saudi Arabia.

The present study is intended to provide novel combinations of ITS primers that are both species- and strain- specific. Also, ITS1 and ITS4 region sequences will be utilized to identifyTrichoderma species, assess its genetic diversity, and determine if the geographic locations have a probable role in shaping Trichoderma's genetic diversity.

\section{Materials and methods}

A total of 36 Trichoderma isolates were collected from Egypt and Saudi Arabia across various geographic locations (Fig. 1). Potato dextrose agar (PDA) medium was used to culture the Trichoderma isolates, and it is containing $4 \mathrm{~g}$ potato extract, $20 \mathrm{~g}$ dextrose, and $15 \mathrm{~g}$ agar.

\section{DNA extraction, polymerase chain reaction, and electrophoresis \\ Genomic DNA isolation}

Trichoderma isolates were cultured on Czapek Dox broth at $28^{\circ} \mathrm{C}$ for 5 days. Czapek Dox broth media contain $30 \mathrm{~g}$ sucrose, $3 \mathrm{~g}$ sodium nitrate, $1 \mathrm{~g}$ dipotassium phosphate, $0.5 \mathrm{~g}$ magnesium sulfate, $0.5 \mathrm{~g}$ potassium chloride, and $0.01 \mathrm{~g}$ ferrous sulfate, and $\mathrm{pH}$ was adjusted to 7.3. The total genomic DNA for each strain was extracted, using the Norgen Plant/Fungi DNA Isolation Kit (Sigma, Thorold, Canada) as previously described in Hassan et al. (2019). The genomic DNA was subsequently used for sequencing.

\section{PCR amplification of ITS region}

ITS1 and ITS4 regions at the $5.8 S$ rDNA gene from all specimens were amplified, using the primer pair ITS-1 (5' ${ }^{\prime}$ TCC GTA GGT GAA CCT GCG G-3') and ITS-4 (5'-TCC TCC GCT TAT TGA TAT GC-3') as suggested by Hermosa et al. (2000) and Hassan (2014). PCR was performed as described in Hassan et al. (2019), in PCR tubes containing $1 \mu \mathrm{l}(10 \mathrm{ng})$ of genomic DNA, $12.5 \mu \mathrm{l}$ of $\mathrm{GoTaq}^{\circledR}$ Green Master Mix (Promega, Madison, WI, USA), $1 \mu \mathrm{l}$ of each primer $(20 \mathrm{pmol})$, and deionized distilled water (up to a total volume of $25 \mu \mathrm{l}$ ). For DNA amplification, the tube contents were heated at $94^{\circ} \mathrm{C}$ for $10 \mathrm{~min}$ in a C1000 Touch $^{\mathrm{Tm}}$ Thermal Cycler (Bio-Rad, Munich, Germany). Subsequently, Taq polymerase was added, followed by 35 cycles of $1 \mathrm{~min}$ at $94^{\circ} \mathrm{C}, 45 \mathrm{~s}$ at $60^{\circ} \mathrm{C}$, and $1 \mathrm{~min}$ at $72^{\circ} \mathrm{C}$, with a final 7 -min extension at $72^{\circ} \mathrm{C}$.

\section{DNA sequence analysis}

The nucleotide sequences of the 5.8S-ITS region were determined, using the Gene analyzer 3121 sequencing service (Macrogen Co., Seoul, South Korea). The deduced 36 sequences were subjected to the National Center for Biotechnology Information (NCBI) BLAST search tool (http://blast.ncbi.nlm.nih.gov) to detect sequence similarity. Each sequence was individually BLAST searched, where BLAST results with the lowest expected 

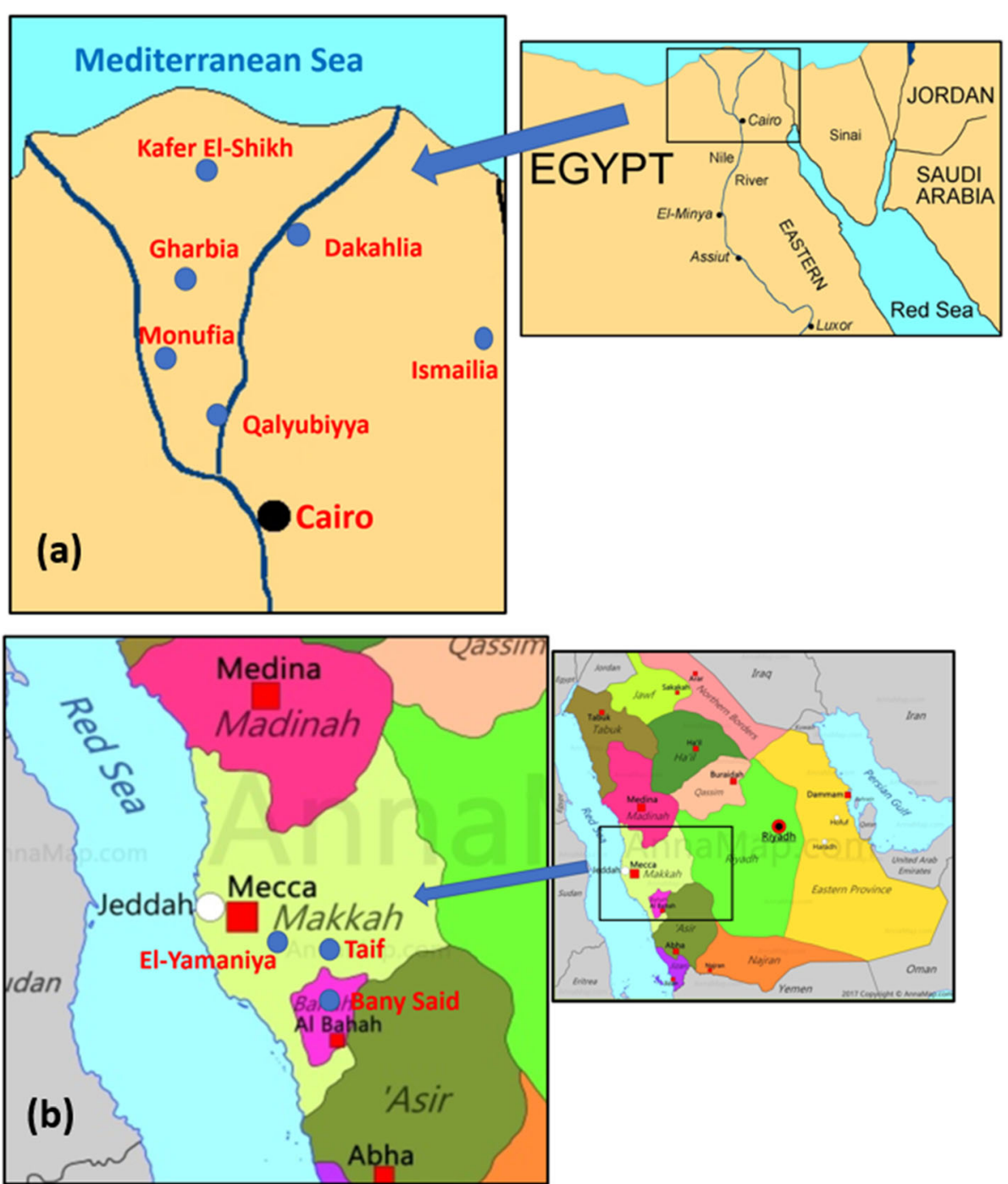

Fig. 1 A map showing the geographical locations where a Egyptian and $\mathbf{b}$ Saudi Arabian samples were collected

value ( $e$ value) which indicates the number of nonchanced alignments were selected. To ensure that BLAST outputs were governed by $e$ values, BLAST algorithm parameters were decreased such that the expected threshold was set to a more stringent value of $1 \mathrm{e}^{-6}$. Alignment and editing of the 36 sequences were carried out using Clustal $x$ version 2 (Larkin et al. 2007).

\section{Phylogenetic analyses}

Exploratory data and phylogenetic analyses were carried out using R Project for Statistical Computing (R Core Team 2017). Exploratory data analysis was performed using Seqinr (Charif and Lobry 2007) R package. Phylogenetic analyses were carried out by ape package (Paradis et al. 2004). Reconstruction of the phylogenetic tree was performed using the neighbor-joining method (Nei and Gojobori, 1986).

\section{Nucleotide diversity}

To determine the level of sequence variability, the following common genetic parameters were estimated for sequences from specimens originating from Egypt and Saudi Arabia: haplotype diversity $\left(H_{\mathrm{d}}\right)$, number of polymorphic sites $(S)$, nucleotide diversity per site $\left(\theta_{\mathrm{w}}\right)$, and nucleotide diversity $\left(\pi_{\mathrm{T}}\right)$. The DnaSP v5.10 (Librado and Rozas 2009) was used for the above computation.

\section{Isolation-by-distance}

The degree of isolation-by-distance (IBD) (Rousset 1997) was assessed by testing the association between geographic and genetic distances for all pairs of isolates within each group of sequences. Pairwise geographical distances among isolates were calculated using the GPS coordinates at the sampling localities in the Geographic 
Distance Matrix Generator v. 1.2.3 (Ersts 2010). Geographic isolation-by-distance referred to the idea that isolates may be spatially distributed across regions. This term sought to determine if there is a statistically significant relationship between genetic distance and geographic distance and the strength of this relationship. Following the regression method of Rousset (1997), geographic distances were log-transformed and genetic distances were expressed as $\Phi_{\mathrm{ST}}$. The statistical significance of the associations was assessed based on a Mantel test (Mantel 1967) with 1000 permutations, using GenAlEx 6.5 (Peakall and Smouse 2012).

\section{Results and discussion}

\section{Trichoderma species identification}

The growth pattern of all 36 Trichoderma strains (24 and 12 isolates from Egypt and Saudi Arabia, respectively) cultured on PDA was monitored, and their proliferation pattern revealed significant changes (data not shown). Oligonucleotide barcode is a powerful tool for the identification of Trichoderma species and is recommended as an alternative or alongside morphological methods (Hassan et al. 2019). Molecular data from ITS sequences provided accurate characterization and identification of isolates. However, hereafter, isolates will be referred to as Saudi Arabian isolates or Egyptian isolates, regardless of the sampling location. Tables 1 and 2 showed the results obtained from NCBI BLAST queries for the 36 isolates.

The criteria used to query sequences aimed to reduce the search space (database). For the 36 isolates queries, $E$ values were 0 , which indicated non-chanced alignments of the queries. For Egyptian isolates, the percentage identity with similar species ranged between 84 and $100 \%$, while Saudi Arabian isolates showed similarities with similar species ranged between 97 and 99\%. Trichoderma isolates were deposited in a gene bank with accession numbers MK680258-MK680293. Moreover, the NCBI BLAST query of Egyptian isolates resulted in 7 Trichoderma species, namely $T$. bissettii, $T$. crassum, $T$. lentiforme, T. longibrachiatum, T. neokoningii, T. pseudokoningii, and T. yunnanens. Of the 24 Egyptian isolates, 11 were identified as $T$. lentiforme, 7 were $T$. longibrachiatum, 2 were $T$. neokoningii, and only one isolate of each species ( $T$. bissettii, T. crassum, T. pseudokoningi, and T. yunnanense) (Table 1). For the Saudi

Table 1 Location and BLAST search results for Trichoderma isolates from Egypt and their similarity with the most similar species

\begin{tabular}{|c|c|c|c|c|c|c|}
\hline Isolate no. & Location & Species & Accession number & NCBI best match & Percent of identity & $E$ value \\
\hline 1 & Kafer El-Shikh & T. bissettii & MK680258 & T. bissettii & 99 & 0 \\
\hline 2 & Kafer El-Shikh & T. crassum & MK680259 & T. crassum & 99 & 0 \\
\hline 3 & Gharbia & T. lentiforme & MK680260 & T. lentiforme & 99 & 0 \\
\hline 4 & Gharbia & T. lentiforme & MK680261 & T. lentiforme & 99 & 0 \\
\hline 5 & Kafer El-Shikh & T. lentiforme & MK680262 & T. lentiforme & 99 & 0 \\
\hline 6 & Kafer El-Shikh & T. lentiforme & MK680263 & T. lentiforme & 99 & 0 \\
\hline 7 & Kafer El-Shikh & T. lentiforme & MK680264 & T. lentiforme & 84 & $6 E-140$ \\
\hline 8 & Kafer El-Shikh & T. lentiforme & MK680265 & T. lentiforme & 98 & 0 \\
\hline 9 & Dakahlia & T. lentiforme & MK680266 & T. lentiforme & 99 & 0 \\
\hline 10 & Dakahlia & T. lentiform & MK680267 & T. lentiforme & 99 & 0 \\
\hline 11 & Gharbia & T. lentiforme & MK680268 & T. lentiforme & 99 & 0 \\
\hline 12 & Gharbia & T. lentiforme & MK680269 & T. lentiforme & 100 & 0 \\
\hline 13 & Gharbia & T. lentiforme & MK680270 & T. lentiforme & 99 & 0 \\
\hline 14 & Kafer El-Shikh & T. longibrachiatum & MK680271 & T. longibrachiatum & 99 & 0 \\
\hline 15 & Kafer El-Shikh & T. longibrachiatum & MK680272 & T. longibrachiatum & 99 & 0 \\
\hline 16 & Gharbia & T. longibrachiatum & MK680273 & T. longibrachiatum & 99 & 0 \\
\hline 17 & Gharbia & T. longibrachiatum & MK680274 & T. longibrachiatum & 99 & 0 \\
\hline 18 & Monufia & T. longibrachiatum & MK680275 & T. longibrachiatum & 99 & 0 \\
\hline 19 & Monufia & T. longibrachiatum & MK680276 & T. longibrachiatum & 99 & 0 \\
\hline 20 & Monufia & T. longibrachiatum & MK680277 & T. longibrachiatum & 99 & 0 \\
\hline 21 & Dakahlia & T. neokoningii & MK680278 & T. neokoningii & 99 & 0 \\
\hline 22 & Dakahlia & T. neokoningii & MK680279 & T. neokoningii & 99 & 0 \\
\hline 23 & Ismailia & T. pseudokoningi & MK680280 & T. pseudokoningii & 99 & 0 \\
\hline 24 & Ismailia & T. yunnanense & MK680281 & T. yunnanens & 99 & 0 \\
\hline
\end{tabular}


Table 2 Location and BLAST search results for Trichoderma isolates from Saudi Arabia and their similarity with the most similar species

\begin{tabular}{lllllll}
\hline Isolate no. & Location & Species & Accession number & NCBI best match & Percent of identity & $E$ value \\
\hline 1 & Taif government & T. longibrachiatum & MK680282 & T. longibrachiatum & 99 & 0 \\
2 & Taif government & T. longibrachiatum & MK680283 & T. longibrachiatum & 99 & 0 \\
3 & Taif government & T. longibrachiatum & MK680284 & T. longibrachiatum & 99 & 0 \\
4 & Taif government & T. longibrachiatum & MK680285 & T. longibrachiatum & 99 & 0 \\
5 & El-Yamaniya, Makkah & T. longibrachiatum & MK680286 & T. longibrachiatum & 99 & 0 \\
6 & El-Yamaniya, Makkah & T. longibrachiatum & MK680287 & T. longibrachiatum & 99 & 0 \\
7 & El-Yamaniya, Makkah & T. longibrachiatum & MK680288 & T. longibrachiatum & 99 & 0 \\
8 & El-Yamaniya, Makkah & T. longibrachiatum & MK680289 & T. longibrachiatum & 99 & 0 \\
9 & Taif government & T. lentiforme & MK680290 & T. lentiforme & 99 & 0 \\
10 & Bany Said, Al-Baha & T. simmonsii & MK680291 & T. simmonsii & 99 & 0 \\
11 & Bany Said, Al-Baha & T. simmonsii & MK680292 & T. simmonsii & 99 & 0 \\
\hline
\end{tabular}

Arabian isolates, only 4 Trichoderma species were identified, T. longibrachiatum, T. lentiforme, T. simmonsii, and T. pseudokoningii. Of the 12 Saudi Arabian isolates, 8 belonged to T. longibrachiatum, 2 belonged to T. simmonsii, and only one belonged to each of T. pseudokoningii and T. simmonsii (Table 2). Comparing species found among Egyptian isolates with their counterparts in Saudi Arabia, T. simmonsii was found only among Saudi Arabian isolates, and T. bissettii, T. crassum, T. neokoningii, and T. yunnanens only appeared in Egyptian isolates. BLAST search at NCBI was used to match the nucleotide sequences of all eight Trichoderma species for the post-molecular identification validation. This confirmed the selected sequences as specific strains of Trichoderma species (Srivastava et al. 2014; Mazrou et al. 2020). A set of 5 oligonucleotide sequences present in all known Hypocrea/Trichoderma ITS1 - 5.8S RNA ITS4 sequences, was used in combination to identify the species at a genetic level (Hassan 2014; Hassan et al. 2019). Using molecular markers, particularly those based on DNA sequenced data, was an essential technique to decipher the genetic variability of any species (Nagy et al. 2004; Bellemain et al. 2010). In addition, the interspecies identification of the species from different isolates was carried out in this study. The results showed that although the rDNA ITS sequence was very conservative, there were variations on sequence and length among different isolates, and there was a genetic differentiation at various levels. Therefore, the ITS sequence analysis clearly differentiated between Egyptian and Saudi Arabian species. Similarly, Kuhls et al. (1997) used sequence analysis to differentiate between $T$. reesei and T. longibrachiatum. Many other researchers have used ITS sequences to identify Trichoderma spp. (Sharma et al. 2009; Shahid et al. 2013). Consequently, variation among individuals of the same species was noticed (Fahmi et al. 2016; Hassan et al. 2019; Mazrou et al.
2020); therefore, it is of great interest to identify the species at the molecular level.

\section{Sequence variations}

Sequence length varied greatly among the isolates. For the Egyptian isolates, the shortest sequence length was attributable to T. bissettii of $430 \mathrm{bp}$, while T. yunnanens had the longest length of $874 \mathrm{bp}$. The percentage of GC content was consistent among species, with a similar trend observed for the Saudi Arabian isolates. In Egyptian isolates, the GC content ranged from $55 \%$ for $T$. yunnanens to $58 \%$ for T. longibrachiatum. Similarly, for the Saudi Arabian isolates, the GC content ranged from $55 \%$ in $T$. simmonsii to $59 \%$ in T. pseudokoningii. The base frequencies of Egyptian and Saudi Arabian isolates were presented in Fig. 2a, b. Only 2 species from the Egyptian isolates showed noticeable variation in nucleotide base proportions. Sequences from T. neokoningii and T. yunnanens revealed that the percent of thymine was higher than other bases, and no other noticeable differences were observed. In an earlier study, Abd-Elsalam et al. (2010) observed a slight variation between $T$. harzianum and $T$. longibrachiatum in Saudi Arabian isolates. This indicated a wide range of interspecies variations, which is consistent with the idea of haplotype presence among species (Gupta et al. 2014). Abd-Elhamid et al. (2017) also reported that molecular identification is very important to identify the Trichoderma species, so it is recommended to be used for confirming the morphological approaches in the identification of Trichoderma isolates obtained from Egyptian soils.

\section{Phylogenetic analysis}

Cluster analysis was carried out as a pre-processing step to glean an insight into the data distribution. The results of the cluster analysis were shown in Fig. 3 . The studied 36 isolates formed two large clusters. The first 
(a)

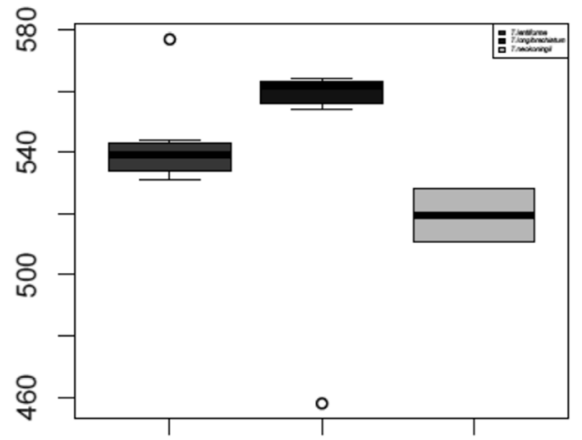

(c)

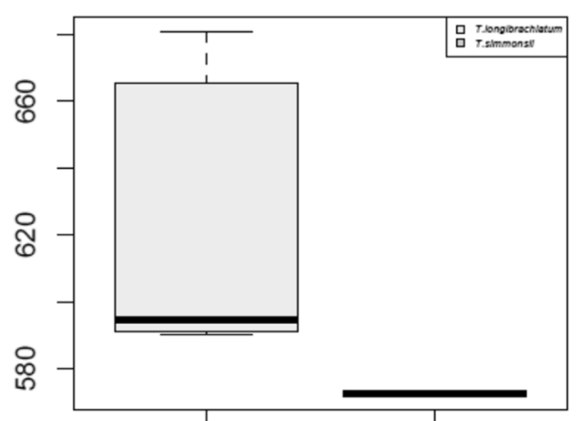

(b)

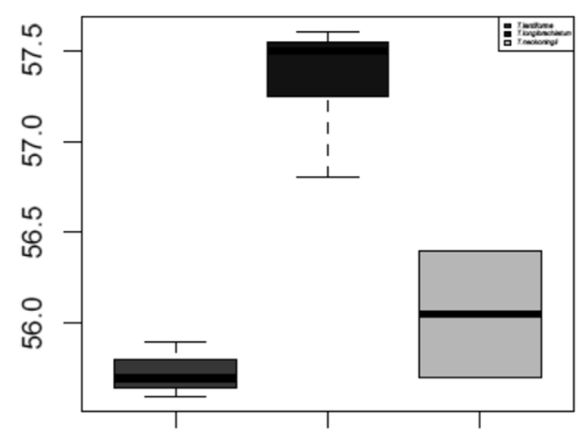

(d)

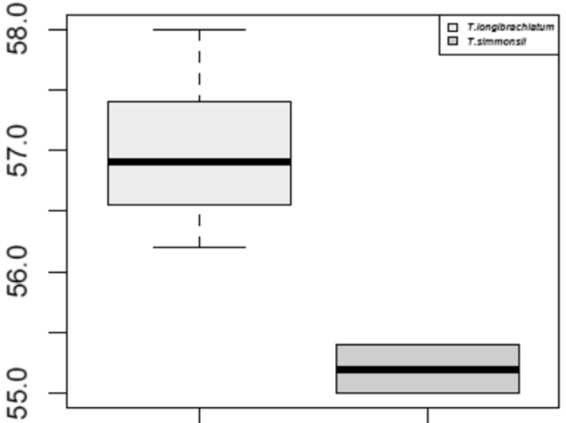

Fig. 2 Sequence length and percent of GC content of frequent species in Egyptian Trichoderma isolates (a, $\mathbf{b})$ and Saudi Arabian Trichoderma isolates $(\mathbf{c}, \mathbf{d})$

comprised all Saudi Trichoderma strains; this cluster was divided into two sub-clusters. One contained all $8 T$. longibrachiatum and T. pseudokoningii, whereas the second comprised T. lentiforme and T. simmonsii. The second cluster comprised all the Egyptian Trichoderma species; this cluster incorporates three sub-clusters. The first comprised T. yunnanens and T. neokoningii. Although the isolates from Saudi Arabia and Egypt were grouped into different groups (Hassan et al. 2014; Fahmi et al. 2016), the Egyptian isolates showed more uniform patterns of clustering. T. lentiforme isolates from Egypt were grouped into one cluster; however, $T$. crassum was grouped with T. lentiforme Egyptian isolates. These results were similar to those obtained by Anees et al. (2010) in Pakistan, Abd-Elsalam et al. (2010) in Saudi Arabia, Hassan et al. (2014) in Egypt, and Lakhani et al. (2016) in India. Furthermore, T. longibrachiatum grouped with $T$. pseudokoningii in Saudi Arabian isolates. Besides, T. lentiforme and T. crassum grouped; however, they were subdivided into different subgroups. In an earlier study, Cázares-Garcia et al. (2013) and Hassan et al. (2014) observed a little variation between $T$. lentiforme and $T$. longibrachiatum. The low genetic differentiation among isolates from different regions is indicative of shred isolates between the two regions, nevertheless maintaining high genetic variability within each group.

\section{Polymorphism and genetic diversity among species}

The number of haplotypes identified among KSA isolates was higher than that of Egyptian isolates (11 and 8, respectively) (Table 3).

Also, the Saudi Arabian isolates showed 98\% haplotype diversity compared to $76 \%$ among Egyptian isolates. However, the Saudi Arabian isolates showed lower nucleotide diversity $\left(\pi_{\mathrm{T}}\right)$ than their Egyptian counterparts.

AMOVA showed significant differentiation between Saudi Arabian and Egyptian isolates with the most genetic variance observed between rather than within regions. Also, it showed a significant genetic differentiation between the two groups $\left(\Phi_{\mathrm{ST}}=0.838\right.$, Table 4$)$.

Most of the genetic variation was attributed to the between-group differences $(83.77 \%)$. The highest genetic differentiation between isolates in the regions sampled was indicative of the presence of unique species in the two regions. This result was also supported by both cluster and phylogenetic analysis (Fig. 3). Additionally, the statistical analysis revealed further support of the presence of unique isolates where most of the genetic 


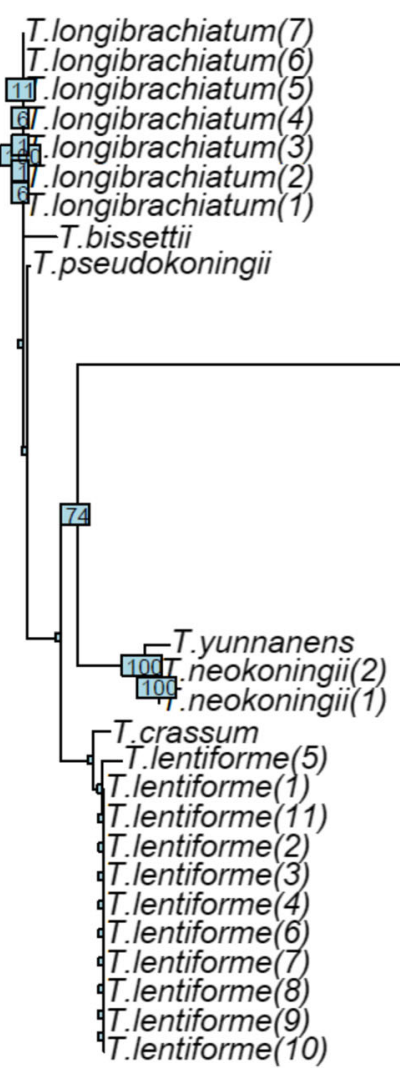

T.lentiforme (ksa)

-100 simmonsii(ksa)(2)

100 simmonsii (ksa)(1)

97. longibrachiatum (ksa) (8)

91 .longibrachiatum(ksa) (7) 11.longibrachiatum (ksa)(6) 荡T.longibrachiatum (ksa) (5)

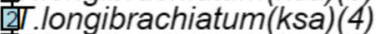
17.longibrachiatum (ksa) (3) T.longibrachiatum(ksa)(2) 4 T.longibrachiatum(ksa)(1)

Fig. 3 Phylogenetic tree of Egyptian and Saudi Arabian Trichoderma isolates using the neighbor-joining method. Bootstrap values are shown in small boxes on each node

variance explained between the region's differences (Sharma et al. 2009; Shahid et al. 2013; Mazrou et al. 2020).

\section{Isolation-by-distance}

The Mantel test showed no correlation between the genetic and geographic distances in Egyptian and Saudi Arabian isolates $\left(r^{2}=-0.38, r^{2}=0.23, P>0.05\right.$ for Egyptian and Saudi Arabian isolates, respectively) (Fig. 4a, b). The lack of correlation between genetic and geographic distances was indicative of the absence of isolation-by-distance pattern among isolates from the two regions. The observed pattern

Table 3 Nucleotide diversity estimates in Trichoderma isolates from Egypt and KSA, standard error between brackets

\begin{tabular}{lll}
\hline & Egypt & KSA \\
\hline Number of isolates & 24 & 12 \\
Number of haplotypes $(H)$ & 8 & 11 \\
Haplotype diversity $\left(H_{d}\right)$ & $0.757(0.027)$ & $0.985(0.012)$ \\
Number of polymorphic sites $(S)$ & 51 & 35 \\
Nucleotide diversity per site $\left(\theta_{\mathrm{w}}\right)$ & $0.0367(0.002)$ & $0.0259(0.003)$ \\
Nucleotide diversity $\left(\pi_{\mathrm{T}}\right)$ & $0.052(0.002)$ & $0.030(0.002)$ \\
\hline
\end{tabular}

suggested the presence of high gene flow within each of the studied regions.

DNA sequencing of the 5.8S-ITS region was carried out, using specific primers within ITS1 and ITS4. The ITS region is one of the most reliable loci for the identification of a strain at the species level (Kullnig-Gradinger et al. 2002; Hassan 2014; Hassan et al. 2019). By comparing the sequences of the 5.8S-ITS region to the sequences deposited in GenBank, all the Trichoderma isolates can be identified to the species level with a homology percentage of at least $99 \%$. The TrichOKEY search tool, a program specifically comparing ITS1 and ITS4 sequences to a specific database for Trichoderma generated from only vouchered sequences, was used to assess

Table 4 Analysis of molecular variance (AMOVA) and fixation index $\Phi_{\text {ST }}$ among 21 Trichoderma isolates collected from KSA and Egypt

\begin{tabular}{llllll}
\hline $\begin{array}{l}\text { Source of } \\
\text { variation }\end{array}$ & df & $\begin{array}{l}\text { Sum of } \\
\text { squares }\end{array}$ & $\begin{array}{l}\text { Variance } \\
\text { component }\end{array}$ & $\%$ variation & $\boldsymbol{\Phi}_{\text {ST }}$ \\
\hline Between regions & 1 & 2633.819 & 162.644 & 83.770 & $0.838^{*}$ \\
Within regions & 34 & 1071.458 & 31.513 & 16.230 & \\
Total & 35 & & & & \\
\hline${ }^{*} P<0.05$ & & & & & \\
\end{tabular}


(a)

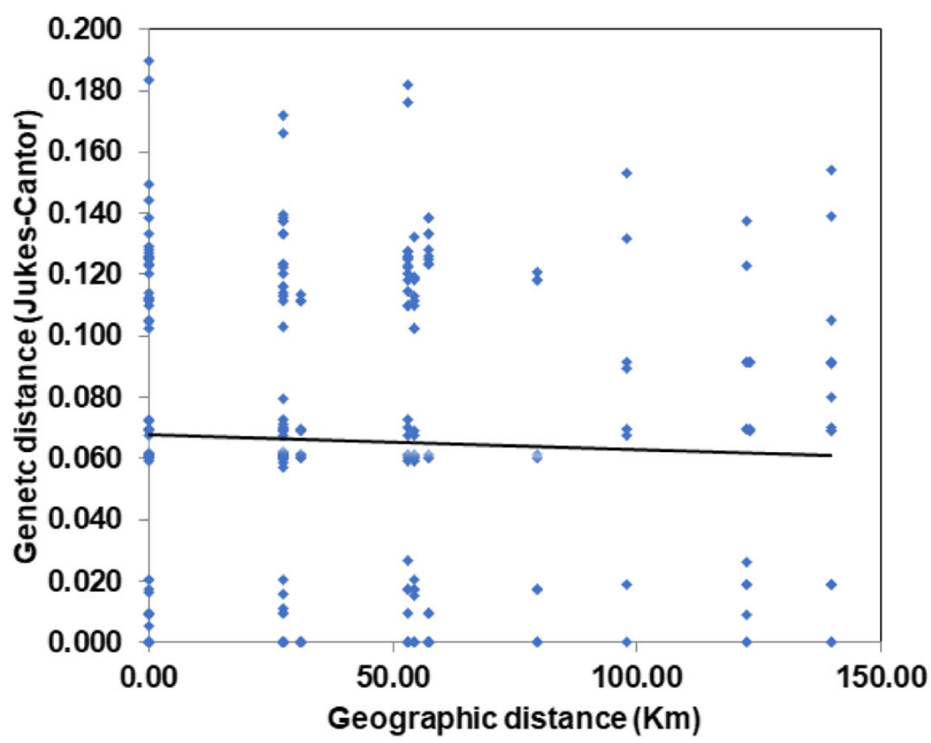

(b)

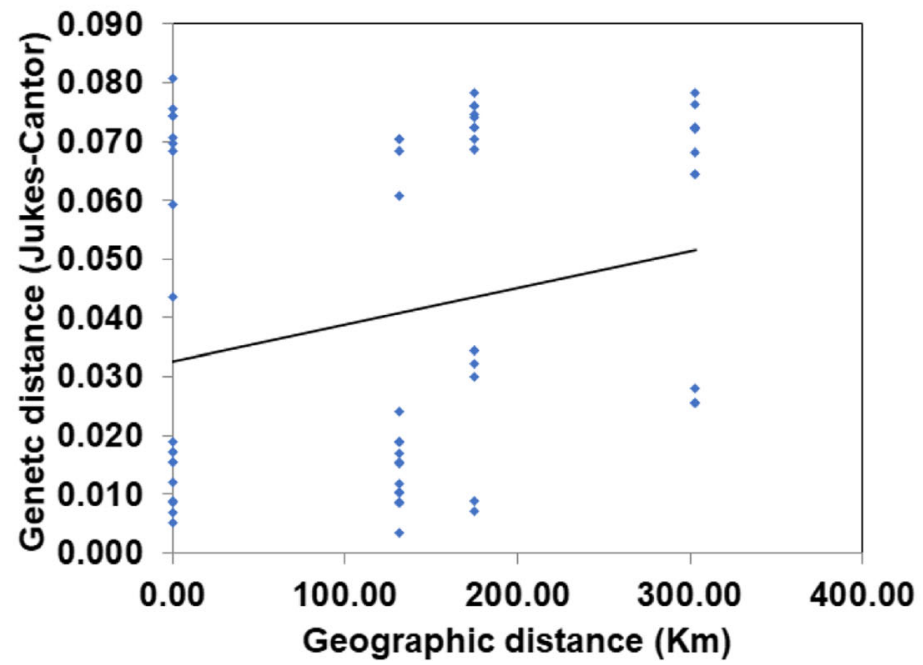

Fig. 4 Isolation-by-distance in Trichoderma isolates obtained from a Egypt and b Saudi Arabia. Genetic distance (Jukes-Cantor) vs. geographical distance $(\mathrm{km})$, showing the regression line

the reliability of BLAST results. TrichOKEY has resulted in the successful identification of Trichoderma isolates (Anees et al. 2010; Hassan et al. 2014; Lakhani et al. 2016).

\section{Conclusion}

The obtained results have confirmed the efficiency and reproducibility of ITS as a powerful tool for the identification and genetic diversity assessment of Trichoderma spp. Egyptian isolates showed a more uniform phylogenetic pattern than Saudi Arabian isolates. Geographical differences have a significant impact on genetic differentiation of the local isolates where the most of genetic differences occurred among rather than within groups.

\section{Abbreviations}

ITS: Internal transcribed spacer; NCBI: National Center for Biotechnology Information; BLAST: Basic Local Alignment Search Tool; AMOVA: Analysis of molecular variance; IBD: Isolation-by-distance; PCR: Polymerase chain reaction

\section{Acknowledgements}

The authors extend their appreciation to the Deanship of Scientific Research at King Khalid University for funding this work through the Program of Research Groups under grant number (project number 2/28/1440). The current work was also funded by Taif University Researchers Supporting Project number (TURSP - 2020/59), Taif university, Taif, Saudi Arabia.

\section{Authors' contributions}

All authors contributed significantly to this research and preparation of the manuscript. This study was conceived and designed by YM, AM, and MI. The laboratory work was carried out by $\mathrm{MH}, \mathrm{AB}$, and $\mathrm{AH}$. Data were analyzed by $\mathrm{YM}, \mathrm{AS}$, and $\mathrm{MI}$. The manuscript was written by $\mathrm{AK}, \mathrm{MI}$, and $\mathrm{AS}$. The manuscript was revised by $A B$ and $A H$. All authors have reviewed and agreed upon the final version of the manuscript. 


\section{Funding}

The current work was funded by both King Khalid University ,under grant number (2/28/1440) and by Taif University Researchers Supporting Project number (TURSP -2020/59), Taif university, Taif, Saudi Arabia.

\section{Availability of data and materials}

All data generated or analyzed during this study are included in this published article.

\section{Ethics approval and consent to participate}

Not applicable.

\section{Consent for publication}

Not applicable.

\section{Competing interests}

The authors declare that they have no competing interests.

\section{Author details}

'Department of Business Administration, Community College, King Khaled University, P.O. Box 678, Abha 22873, Saudi Arabia. ${ }^{2}$ Department of Agricultural Economics, Faculty of Agriculture, Tanta University, Tanta, Egypt ${ }^{3}$ Department of Biology, College of Science, Taif University, P.O. Box 11099, Taif 21944, Saudi Arabia. ${ }^{4}$ Department of Botany, Faculty of Agriculture, Menoufia University, Sheben El-Kom, Menoufia Government, Egypt. ${ }^{5}$ Deptartment of Cell Biology, National Research Center, Dokki, Giza, Egypt. ${ }^{6}$ Department of Genetics, Faculty of Agriculture, Menoufia University, Sheben El-Kom, Menoufia Government, Egypt.

Received: 10 June 2020 Accepted: 9 September 2020

\section{Published online: 29 September 2020}

\section{References}

Abd-Elhamid MI, Ismail Ml, Alshishtawy HM, Sedik MZ (2017) Identification and molecular characterization of Egyptian Trichoderma isolates. Biosci res 14: $1156-1166$

Abd-Elsalam KA, Almohimeed I, Moslem MA, Bahkali AH (2010) M13-microsatellite PCR and rDNA sequence markers for identification of Trichoderma (Hypocreaceae) species in Saudi Arabian soil. Gen Molecul Res 9:2016-2024

Anees M, Tronsmo A, Hermann V, Hjeljord LG, Heraud C, Steinberg C (2010) Characterization of field strains of Trichoderma antagonistic against Rhizoctonia solani. Fungal Biol 114:691-701

Atanasova L, Crom SL, Gruber S, Coulpier F, Seidl-Seiboth V, Kubicek C, Druzhinina I (2013) Comparative transcriptomics reveals different strategies of Trichoderma mycoparasitism. BMC Genomics 14:121-128

Bellemain E, Carlsen T, Brochmann C (2010) ITS as an environmental DNA barcode for fungi: an in-silico approach reveals potential PCR biases. BMC Microbiol 10:189

Cázares-Garcia SV, Vázquez-Garciduenãs MS, Vázquez-Marrufo G (2013) Structural and phylogenetic analysis of laccases from Trichoderma: a bioinformatic approach. PLoS ONE 8:e55295

Charif D, Lobry RJ (2007) SeqinR 1.0-2: a contributed package to the R project for statistical computing devoted to biological sequences retrieval and analysis. Biomed Engin 34:207-232

Ersts PJ (2010) Geographic Distance Matrix Generator v. 1.2.3. Available online: http://biodiversityinformatics.amnh.org/open_source/gdmg

Fahmi Al, Eissa RA, El-Halfawi KA, Hamza HA, Helwa MS (2016) Identification of Trichoderma spp. by DNA barcode and screening for cellulolytic activity. J Microb Biochem Technol 8:202-209

Gupta VG, Schmoll M, Herrera-Estrella A, Upadhyay RS, Druzhinina I (2014) Biotechnology and biology of Trichoderma. Elsevier 5:16-332

Hassan MM (2014) Influence of protoplast fusion between two Trichoderma spp. on extracellular enzymes production and antagonistic activity. Biotechnol Biotechnol Equip 28:1014-1023

Hassan MM, Farid MA, Gaber A (2019) Rapid identification of Trichoderma koningiopsis and Trichoderma longibrachiatum using sequence characterized amplified region markers. Egypt J Biol Pest Control 29:13

Hassan MM, Gaber A, El-Hallous El (2014) Molecular and morphological characterization of Trichoderma harzianum from different Egyptian soils. Wulfenia J 21:80-96
Hermosa MR, Grondona I, Iturriaga EA, Diaz-Minguez JM, Castro C, Monte E (2000) Molecular characterization and identification of biocontrol isolates of Trichoderma spp. Appl Environ Microbiol 66:1890-1898

Kredics L, Hatvani L, Naeimi S, Körmöczi P, Manczinger L, Vágvölgyi C, Druzhinina I (2014) Biodiversity of the genus Hypocrea/Trichoderma in different habitats. In: Gupta VK, Schmoll M, Herrera-Estrella A, Upadhyay RS, Druzhinina I, Tuohy MG (eds) Biotechnology and biology of Trichoderma. Elsevier, London, pp 3-24

Kuhls K, Lieckfeldt E, Samuels GJ (1997) Revision of Trichoderma section Longibrachiatum including related teleomorphs based on an analysis of ribosomal DNA internal transcribed spacer sequences. Mycologia 89:442-460

Kullnig-Gradinger CM, Szakacs G, Kubicek CP (2002) Phylogeny and evolution of the genus Trichoderma: a multigene approach. Mycol Res 106:757-767

Lakhani HN, Vakharia DN, Hassan MM (2016) Fingerprinting and molecular comparison among two parental strains of Trichoderma spp. and their corresponding fusants produced by protoplast fusion. Biotechnol Biotechnol Equip 30:1065-1074

Larkin MA, Blackshields G, Brown NP, Chenna MGPA, McWilliam H, Valentin F, Wallace IM, Wilm A, Lopez R, Thompson JD, Gibson TJ, Higgins DG (2007) Clustal W and Clustal X version 2.0. Bioinformatics 23:2947-2948

Librado P, Rozas J (2009) DnaSP v5: a software for comprehensive analysis of DNA polymorphism data. Bioinf 25:1451-1452

Mantel NA (1967) The detection of disease clustering and a generalized regression approach. Cancer Res 27:209-220

Mazrou Y, Makhlouf A, Elseehy M, Awad M, Hassan M (2020) Antagonistic activity and molecular characterization of biological control agent Trichoderma harzianum from Saudi Arabia. Egypt J Biol Pest Control 30:4

Nagy E, Kredics L, Antal Z, Papp T (2004) Molecular diagnosis, epidemiology and taxonomy of emerging medically important filamentous fungi. Rev Med Microbiol 15:153-162

Nei M, Gojobori T (1986) Simple methods for estimating the numbers of synonymous and nonsynonymous nucleotide substitutions. Mol Biol Evol 3: 418-426

Paradis E, Claude J, Strimmer J (2004) APE: analyses of phylogenetics and evolution in R language. Bioinformatics 20:289-290

Parmar HJ, Hassan MM, Bodar NP, Umrania W, Patel SV, Lakhani HN (2015) In vitro antagonism between phytopathogenic fungi Sclerotium rolfsii and Trichoderma strains. Int J Appl Sci Biotechnol 3:16-19

Peakall R, Smouse PE (2012) GenAlEx 6.5: genetic analysis in Excel. Population genetic software for teaching and research-an update. Bioinformatics 28 . 2537-2539

Rousset F (1997) Genetic differentiation and estimation of gene flow from F-statistics under isolation by distance. Genetics 145:1219-1228

Schoch CL, Seifert KA, Huhndorf S (2012) Nuclear ribosomal internal transcribed spacer (ITS) region as a universal DNA barcode marker for Fungi. Proc Natl Acad Sci 109:6241-6246

Shahid M, Srivastava M, Sharma A (2013) Morphological, molecular identification and SSR marker analysis of a potential strain of Trichoderma/Hypocrea for production of a bioformulation. J Plant Pathol Microbiol 4:204-210

Sharma K, Mishra AK, Misra RS (2009) Morphological, biochemical and molecular characterization of Trichoderma harzianum isolates for their efficacy as biocontrol agents. J Phytopathol 157:51-56

Srivastava M, Shahid M, Pandey S, Singh A, Kumar V, Gupta S, Maurya M (2014) Trichoderma genome to genomics: a review. J Data Mining Genomics Proteomics 5:162

\section{Publisher's Note}

Springer Nature remains neutral with regard to jurisdictional claims in published maps and institutional affiliations. 